\title{
The hypoxic microenvironment: a driving force for heterotopic ossification progression
}

\author{
Yifei Huang ${ }^{1}$, Xinyi Wang ${ }^{1}$ and Hui Lin ${ }^{2^{*}}$ (D)
}

\begin{abstract}
Heterotopic ossification $(\mathrm{HO})$ refers to the formation of bone tissue outside the normal skeletal system. According to its pathogenesis, $\mathrm{HO}$ is divided into hereditary $\mathrm{HO}$ and acquired $\mathrm{HO}$. There currently lack effective approaches for $\mathrm{HO}$ prevention or treatment. A deep understanding of its pathogenesis will provide promising strategies to prevent and treat HO. Studies have shown that the hypoxia-adaptive microenvironment generated after trauma is a potent stimulus of HO. The hypoxic microenvironment enhances the stability of hypoxia-inducible factor-1a (HIF-1a), which regulates a complex network including bone morphogenetic proteins (BMPs), vascular endothelial growth factor (VEGF), and neuropilin-1 (NRP-1), which are implicated in the formation of ectopic bone. In this review, we summarize the current understanding of the triggering role and underlying molecular mechanisms of the hypoxic microenvironment in the initiation and progression of HO, focusing mainly on HIF-1 and it's influenced genes BMP, VEGF, and NRP-1. A better understanding of the role of hypoxia in $\mathrm{HO}$ unveils novel therapeutic targets for $\mathrm{HO}$ that reduce the local hypoxic microenvironment and inhibit HIF-1a activity.
\end{abstract}

Keywords: Heterotopic ossification, Hypoxic microenvironment, Hypoxia-inducible factor-1a

\section{Background}

Heterotopic ossification ( $\mathrm{HO})$ refers to the presence of bone tissue in muscle or connective tissue. When $\mathrm{HO}$ occurs in the joints, it causes swelling, pain, nerve compression and joint movement disorders. When HO occurs around the spine, it leads to limited spinal activity and spinal cord compression [1]. HO is a common complication after orthopedic surgery in patients with severe trauma $[2,3]$. The pathogenesis of $\mathrm{HO}$ is not fully understood, but studies have proposed three necessary factors for $\mathrm{HO}$ formation: osteogenic precursor cells, multiple inducing factors and related signaling pathways, and an appropriate microenvironment $[4,5]$. In particular, it should be noted that the initiation of $\mathrm{HO}$ requires appropriate local hypoxia in the microenvironment [6, 7].

Tissue damage and hypoxia are usually two simultaneous and related pathological conditions [8]. Hypoxia

* Correspondence: huilin88@ncu.edu.cn

${ }^{2}$ Department of Pathophysiology, School of Basic Medical Sciences,

Nanchang University, 461 BaYi Avenue, Nanchang 330006, Jiangxi Province,

China

Full list of author information is available at the end of the article induces reactions including changes in organ structure, cytokine expression, and the immune response [9]. Studies have demonstrated that the reactions induced by hypoxia are involved in many diseases, such as cancer and $\mathrm{HO}[10,11]$. Hypoxia triggers the formation of $\mathrm{HO}$, in which hypoxia-inducible factor- $1 \alpha$ (HIF- $1 \alpha)$ plays a crucial role $[12,13]$. The most prominent feature under hypoxic conditions is high HIF-1 $\alpha$ activity [14]. Upregulated HIF- $1 \alpha$ modulates the expression of multiple genes, including bone morphogenetic proteins (BMPs), vascular endothelial growth factor (VEGF), and neuropilin-1(NRP-1), which in turn regulate biological processes such as angiogenesis, osteogenesis and bone resorption to induce ectopic bone formation $[13,15,16]$. This review will detail the trigger role and underlying molecular mechanisms of hypoxia in HO. Furthermore, we will highlight a powerful and potential therapeutic target for $\mathrm{HO}$.

\section{Pathogenesis of heterotopic ossification}

$\mathrm{HO}$ is divided into acquired $\mathrm{HO}$ and hereditary $\mathrm{HO}$ depending upon how $\mathrm{HO}$ forms and what causes it 
Table 1 The forms of heterotopic ossification

\begin{tabular}{lllll}
\hline Classification & & obtained form & Cause & Process of formation \\
\hline Inherited HO & FOP & Gene mutations & Gain of function of the ACVR1 gene & Endochondral ossification \\
& PHO & & Loss of function of the GNAS gene & Intramembranous ossification \\
Acquired HO (AHO) & Injury & Injury to nervous system & Distal to injury endochondral and intramembranous ossification \\
& & Injury to musculoskeletal & Near the injury \\
\hline
\end{tabular}

(Table 1) [3]. Acquired $\mathrm{HO}(\mathrm{aHO})$, which is usually induced by musculoskeletal trauma (such as burns, muscle damage and major joint surgery) and neurogenic trauma, can develop through mixed intramembranous and endochondral ossification [17, 18]. Musculoskeletal traumainduced HO often occurs in soft tissues surrounding the injury, while $\mathrm{HO}$ caused by neurogenic trauma occurs away from the injury lesion $[3,19,20]$. There are two types of hereditary HO: fibrodysplasia ossificans progressiva (FOP) and progressive osseous heteroplasia ( $\mathrm{POH})$ [5]; FOP is due to a heterozygous mutation in the ACVR1 gene and involves endochondral ossification to form ectopic bone [21], while $\mathrm{POH}$ is caused by loss of function of the GNAS gene and involves ectopic bone formation through intramembranous ossification [3]. Adaptive microenvironment hypoxia occurs in soft tissue in response to severe trauma and initiates HO formation [12, 13]. A large number of inflammatory cells are recruited at the injury site, and ectopic ossificationrelated cytokines are released, these promote chondrocytes proliferation, cartilage extracellular matrix mineralization and osteoblast differentiation, then cartilage tissue is eventually replaced by ectopic bone $[22,23]$.

Heterotopic ossification ( $\mathrm{HO}$ ) can be divided into acquired $\mathrm{HO}$ and hereditary $\mathrm{HO}$. Acquired $\mathrm{HO}$ usually results from damage to the nervous and skeletal muscle systems, while hereditary $\mathrm{HO}$ comprises FOP and $\mathrm{POH}$, which is caused by genetic mutations in the ACVR1 gene or loss of function of the GANS gene. Acquired $\mathrm{HO}$ is developed by mixed intramembranous ossification and endochondral ossification. Ectopic bone formed near the injury site is induced by skeletal muscle injury, while ectopic bone formation away from the injury site is induced by nervous system injury. Hereditary HO develops through intramembranous ossification or endochondral ossification.

\section{Hypoxia and heterotopic ossification}

Oxygen, an essential source of energy for cellular metabolism and maintenance of the body's biological activities, is transported by the blood throughout body [24]. Hypoxia is the physiological and pathological process of tissue sedation, along with changes in cell metabolism, function and morphology due to insufficient oxygen supply or impaired oxygen use. Hypoxia may involve the whole body or only local tissue [25, 26]. Physiological hypoxia exists in many tissues of the human body, and the hypoxic environment is required for maintaining normal physiological functions, such as liver and bone $[27,28]$. The hypoxic microenvironment is caused mainly by systolic vascular clogging due to inflammatory mediators release after severe trauma resulting in tissue blood circulation disorders and oxygen not being transported throughout the body [29]. In addition, the propagation of intracellular pathogens can cause hypoxia in infected cells [13].

The effect of hypoxia is mediated by HIF-dependent and HIF-independent mechanisms [30, 31]. The HIFindependent pathway mainly causes alterations in protein phosphorylation status. As HIF is a transcription factor, the HIF-dependent pathway regulates downstream genes expression, thereby regulating biological processes, such as angiogenesis and apoptosis [32]. In the absence of oxygen, cell growth and the cell cycle are inhibited, and apoptosis is increased [33]. Moreover, the stability of HIF-1 $\alpha$ protein is increased and the transcription is activated, which effectively induces target genes and enhances the body's adaptation to hypoxic stress and environmental changes [32, 34]. Note that HIF-1 $\alpha$ plays a crucial role in bone development and normal repair [35] Studies have shown that HIF-1 $\alpha$ protein up-regulated by hypoxia not only maintains chondrocyte survival, promotes chondrocyte proliferation [36], participates in chondrocytes differentiation [37], and enhances matrix accumulation in chondrocytes, but also increases VEGF-A protein to generate blood vessels in cartilage, completing normal intrachondral osteogenesis [38]. However, under certain special circumstances, abnormal gene expression due to hypoxia has the opposite effect and creates the right conditions for various diseases, including our focus $\mathrm{HO}$, metabolic disorders, inflammatory diseases and cancers [3942]. Studies have indicated that HIF-1 $\alpha$ with high stability plays an important role in the formation of heterotopic bone in cartilage, which promotes chondrocyte proliferation, hypertrophy and finally differentiate into osteocytes by regulating the expression of BMP, VEGF and other genes [22]. Hypoxia, which is accompanied by soft tissue trauma, is a driving force for the acquisition of acquired or hereditary $\mathrm{HO}[10,43]$. In the local hypoxic microenvironment, HIF is activated, which affects the expression of genes such as BMP, VEGF, and NRP-1 and promotes mesenchymal cell differentiation and ectopic 
bone formation [44, 45]. HIF activation is the trigger for hypoxia-induced heterotopic ossification (Fig. 1). Acquired $\mathrm{HO}$ is caused mostly by tissue damage via hypoxia -induction [7]. Vascular system damage, which leads to immune cell infiltration and proliferation and hence decreased oxygen supply and/or increased oxygen consumption, is often accompanied by tissue hypoxia [46]. The immune response, vascular endothelium, cartilage and bone tissue hyperplasia are all developed under hypoxic conditions [13]. Early ectopic ossification is accompanied by severe tissue hypoxia. In aHO patients, a large number of immune cells and $\mathrm{HO}$ precursor cells are present in lesions [47]. Furthermore, the expression of BMP, HIF-1 $\alpha$, VEGF and other cytokines involved in ectopic bone formation is upregulated [7, 12, 48]. Hypoxia is the main cause of this cellular recruitment and cytokine activation. In addition, in the inflammatory reaction after trauma, bacterial lipopolysaccharide inhibits proline hydroxylase and mediates the transcriptional activation of HIF-1 $\alpha$ [49], further enhancing the expression of genes associated with ectopic bone formation, thereby aggravating induced $\mathrm{HO}$ [50].

Trauma, such as fractures, muscle damage, and burns, is an important cause of the occurrence of HO. When tissue is severely damaged, a local hypoxic microenvironment forms. Under hypoxic stimulation, HIF is activated and regulates the expression of cytokines, promoting the differentiation of ectopic bone precursor cells and mesenchymal cells, into cartilage and osteogenic cells, which ultimately develop into ectopic bone.

Hypoxia is also involved in the development of FOP [13]. Patients with FOP continue to develop ectopic bone after minor trauma [51], similar to $\mathrm{HO}$ induced by nonhereditary trauma. The early stages of ectopic bone formation are associated with active inflammation, immune responses, and the secretion of numerous cytokines [5]. Tissue hypoxia triggers the progression of $\mathrm{HO}$ in FOP [29]. One study found that FOP could directly upregulate BMP expression in connective tissue progenitor cells (CTPCs) independent of Activin A (Act A) in the hypoxic microenvironment to promote ectopic bone formation [52].

\section{Molecular mechanism of hypoxia-induced heterotopic ossification}

The most direct effect of hypoxia-induced $\mathrm{HO}$ is the activation of HIF-1 $\alpha$, which regulates the expression of BMP, VEGF, and Neuropilin-1, thereby inducing angiogenesis, cartilage differentiation, and ultimately ectopic bone formation (Fig. 2).

HIF- $1 \alpha$ is the core and hub of the whole process of $\mathrm{HO}$. The hypoxic microenvironment mainly provides the necessary conditions for the stability of HIF- $1 \alpha$. The HIF- $1 \alpha$ and HIF- $1 \beta$ complex up-regulates BMP and VEGF and down-regulates the expression of NRP-1, all these promote angiogenesis and the proliferation and differentiation of cartilage and osteoblasts and inhibit the proliferation and differentiation of osteoclasts, thereby inducing $\mathrm{HO}$ formation.

\section{Role of the HIF-1a signaling pathway in heterotopic ossification}

The adaptation of cells in response to hypoxia caused by physiological or pathological conditions is mediated by genes that regulate angiogenesis and glycolysis, a phenomenon that is partly faciliated by the HIF family [53]. There are three HIF- $\alpha$ family members in mammals. HIF- $1 \alpha$ is a crucial transcription factor related to

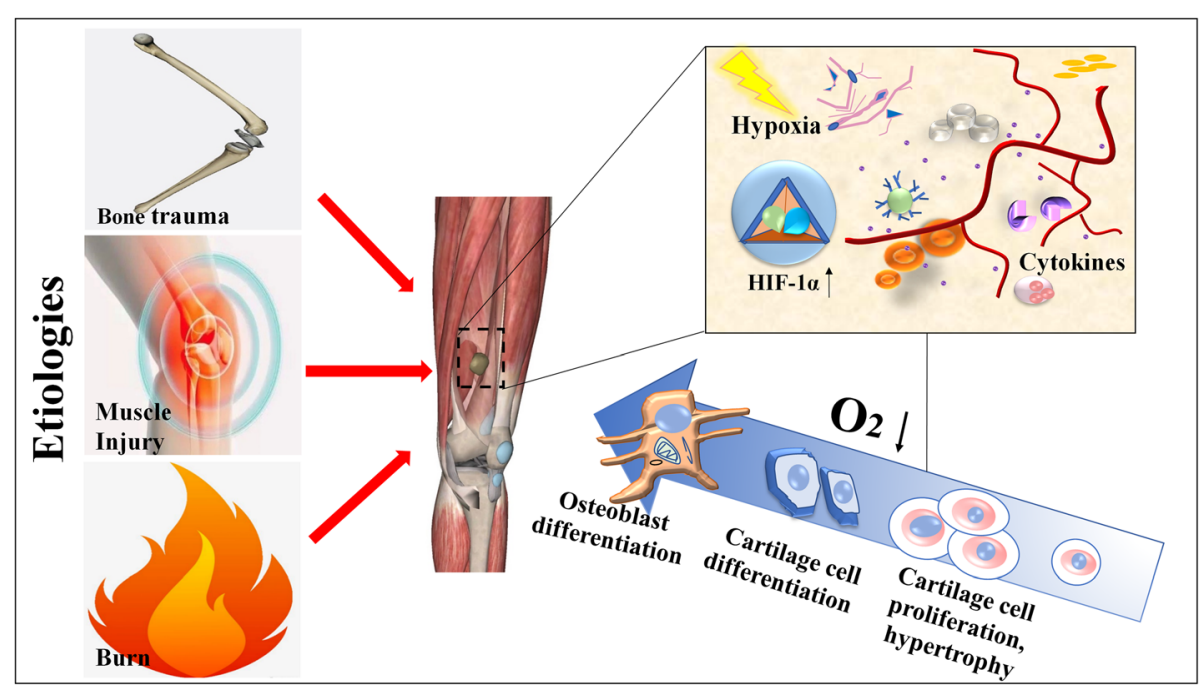

Fig. 1 The role of hypoxia in heterotopic ossification (HO) 


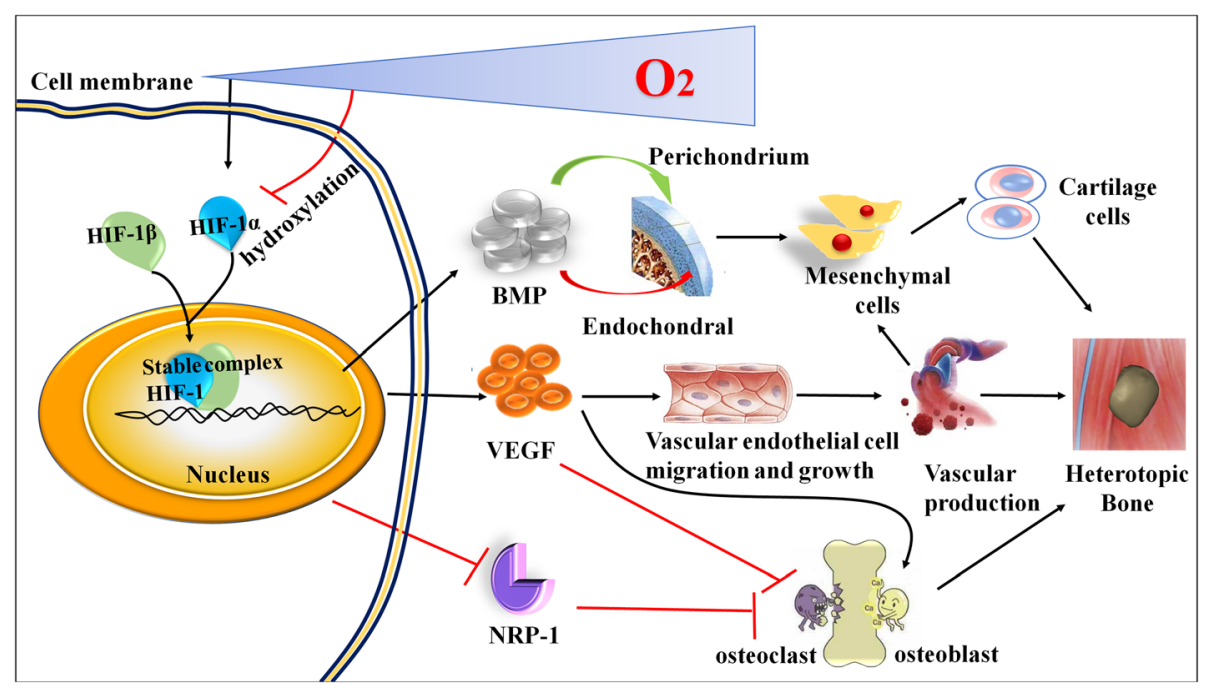

Fig. 2 The specific molecular mechanisms of hypoxia-induced heterotopic ossification ( $\mathrm{HO})$

oxygen homeostasis in the body [49]. Its stability is increased under hypoxia than under normal conditions. For example, trauma-induced $\mathrm{HO}$ usually produces necrotic tissue. Studies have found that necrotic tissue produced by injury has a lower oxygen level than healthy normal tissue $[49,54,55]$. HIF- $2 \alpha$ is restricted to certain tissues [56], and HIF-3 $\alpha$ is a negative regulator of HIF [57].

Under hypoxic conditions, HIF-1 $\alpha$ transcription is activated, which accelerates glycolysis and increases cell survival, inflammation, angiogenesis, and vascular permeability in tissues [58]. The stability of HIF- $1 \alpha$ under hypoxic conditions has been found to recruit $\mathrm{HO}$ precursor cells, promote the proliferation and differentiation of mesenchymal stem cells and induce ectopic bone formation $[7,36]$. Studies have shown that aHO and FOP proceed mainly through the HIF- $1 \alpha$-dependent BMP/SMAD signaling pathway or direct regulation of SOX-9 and Runx-2 expression [12]. In addition, VEGF is thought to amplify the BMP/SMAD signaling pathways to induce ectopic bone formation [15, 22].

In conditions such as hypoxia, signaling factors in the body influence gene transcription and translation, thereby accomplishing certain specialized biological functions. The HIF- $1 \alpha$ and HIF- $1 \beta$ complex has been found to control the translation of three proteins, BMP, VEGF and NRP-1 [59-61], these three proteins promote angiogenesis and the proliferation and differentiation of chondrocytes and osteoblasts, providing the conditions for ectopic bone generation (Fig. 2).

\section{HIF-1 $a$ and BMPs}

BMPs are widespread in the bone matrix, where they play an important role in growth and developmental processes, such as osteogenesis and glycolipid metabolism [62]. BMP signaling is mediated by a heterotetramer formed by two type I receptors and two type II receptors on the cell surface. It recruits and phosphorylates two downstream effectors (R-Smad), which form a heterotrimer with a Co-Smad. This complex then accumulates in the nucleus, where it regulates the expression of different genes [63]. BMP signaling is also mediated by non-Smad signaling pathways, such as the P38 MAPK signaling pathway [64]. BMPs usually induce bone formation through endochondral ossification, where mesenchymal cells in connective tissue first differentiate into cartilage tissue and then calcify into bone [65]. Bone formation can also occur via intramembranous ossification, where mesenchymal cells in connective tissue are spatially oriented, aggregate, and differentiate to form cartilage and bone [62].

BMPs are directly related to the occurrence of $\mathrm{HO}$. Animal studies have shown that $\mathrm{HO}$ is caused by the over-expression of BMPs, especially BMP-2 and BMP-9, in osteoblasts during tissue damage [66, 67]. Rittenberg et al have reported that the inhibition of BMPs reduced $\mathrm{HO}[66]$. Another study has found that blockade of the BMP-9 receptor significantly inhibited ectopic bone formation in damaged muscle [67]. In one clinical study, high levels of BMP-9 expression has been detected in the muscle tissue of patients with traumatic HO [68]. After mild trauma in FOP patients, BMP-4 is also significantly unregulated [69]. Hypoxia in aHO directly upregulates the expression of BMP to some extent, but hypoxia-activated BMP expression has been found to depend on HIF-1 $\alpha$ [59]. The inhibition of HIF- $1 \alpha$ signaling blocks the upregulation of BMP ligands induced by hypoxia [70, 71]. In trauma-induced HO in FOP, hypoxia affects mainly the type I receptor ACVR1 (mutant). 
Studies have shown that hypoxia stimulates oxygen sensors, causing the upregulation of HIF- $1 \alpha$, followed by endocytosis and inhibition of the degradation of cell surface protein kinase receptors. These effects lead to the retention of more mutant ACVR1 (mACVR1) on the cell membrane, prolonging the activation of BMP and enhancing the effect of BMP [59, 72].

\section{HIF-1a and VEGF}

VEGF is a vascular endothelial cell mitogen that binds vascular endothelial cell surface receptors and activates their corresponding pathways to regulate angiogenesis directly [73, 74]. The main biological functions of VEGF are to promote angiogenesis, increase vascular permeability, and maintain normal blood vessels and integrity [75]. VEGF displays functional diversity in tissues through its effects on different receptors and coreceptors. Moreover, studies have found that the expression of VEGF is tissue-specific and context-dependent [76]. Under normal physiological conditions, VEGF is highly expressed in tissues with a high metabolic rate and sufficient blood supply, such as kidney, embryonic tissues and tissues in wound repair [77]. In the absence of oxygen, VEGF secretion is also greatly increased, which promotes the growth and migration of vascular endothelial cells and regulates bone and cartilage formation [78]. Accumulation of HIF- $1 \alpha$ accelerates the release of VEGF cytokines, thereby stimulating blood vessel growth and allowing the body to obtain more nutrients and oxygen during hypoxia $[79,80]$.

Animal studies have shown that the use of exogenous VEGF in mice enhanced the formation of trabecular bone, indicating that VEGF promotes ectopic ossification [81, 82]. In contrast, the number of capillaries at chondrocytes and the formation of ectopic bone is reduced after inhibition of the VEGF activity in mice [83]. Studies have also found that VEGF is involved in endochondral ossification, primarily through its regulation of skeletal muscle cells and the proliferation and differentiation of osteoblasts and osteoclasts. VEGF reduces the number of osteoclasts, enhances the role of osteoblasts and attenuates the role of osteoclasts, thereby directly promoting bone formation [83, 84]. Given the critical role of VEGF in bone formation [85], it is reasonable to assume that under hypoxic conditions, HIF activation and its promotion of ectopic bone formation are associated with the high expression of VEGF.

\section{HIF-1a and Neuropilin-1}

NRP-1, a receptor on the surface of osteoclast precursor cells [86], binds specifically to semaphorin 3A (Sema3A) secreted by osteoblasts and inhibits the immunoreceptor tyrosine-based activation motif (ITAM) co-stimulatory signaling pathway, which in turn inhibits osteoclast differentiation [87]. NRP-1, which is also expressed in endothelial cells, vascular smooth muscle cells and tumor cells, mediates VEGF downstream signaling pathways [88]. The hypoxic microenvironment has been found to inhibit osteoclast differentiation, which is also blocked by the expression of NRP-1 through HIF-1 $\alpha$ [89]. Osteoclasts, the only known cells to date with only bone resorption functions, play an important role in the maintenance of bone homeostasis [90]. Impaired osteoclast differentiation affects bone metabolism and bone resorption [91]. Under physiological conditions, bone marrow is initially in a hypoxic microenvironment. Fractures and inflammation lead to reduced blood flow or oxygen supply and a more obvious pathological hypoxic state [92], which aggravates inhibition of NRP-1 expression and reduces the proliferation and differentiation of osteoclasts [93]. Therefore, we suspect that the abnormally low expression of NRP-1 in the hypoxic environment is one of the important factors that promotes bone formation and ectopic bone formation.

\section{Prevention and treatment of heterotopic ossification}

In general, ectopic bone can be discovered only after it forms and is easily confused with bone tumors. Imagebased examinations, such as bone scans, are generally used to make an accurate diagnosis [94]. Once $\mathrm{HO}$ occurs, the only effective treatment for HO is surgical resection and radiotherapy, but these treatments have many limitations, such as frequent $\mathrm{HO}$ recurrence, poor efficacy, and high cost [95]. Therefore, the principle of $\mathrm{HO}$ treatment should be prevention rather than treatment. Hypoxia is the key factor for the initiation of ectopic bone formation, and a promising strategy for $\mathrm{HO}$ could be management of the hypoxic microenvironment and inhibition of HIF- $1 \alpha$ in the early stage of HO. Hypoxic action has allowed the following four treatment strategies for $\mathrm{HO}$ (Fig. 3).

Strategies for the prevention and treatment of $\mathrm{HO}$ are divided into two major categories: targeting of tissue hypoxia and direct inhibition of HIF-1 $\alpha$. Hypoxia is managed through increased blood circulation, antiinflammatory drugs and moderate joint movements to improve blood circulation disorders and reverse the hypoxic microenvironment. HIF- $1 \alpha$ is mainly downregulated through HIF-1 $\alpha$ inhibitors and the knockout of HIF- $1 \alpha$. We highlight the effects of PX-478 and rapamycin on the prevention and treatment of HO.

We systematically describe how hypoxia promotes ectopic ossification, and emerging mechanistic insights reveals promising strategies for the prevention and treatment of $\mathrm{HO}$.

\section{Management of local hypoxia}

Tissue hypoxia is inextricably linked to the posttraumatic inflammatory response and insufficient blood 


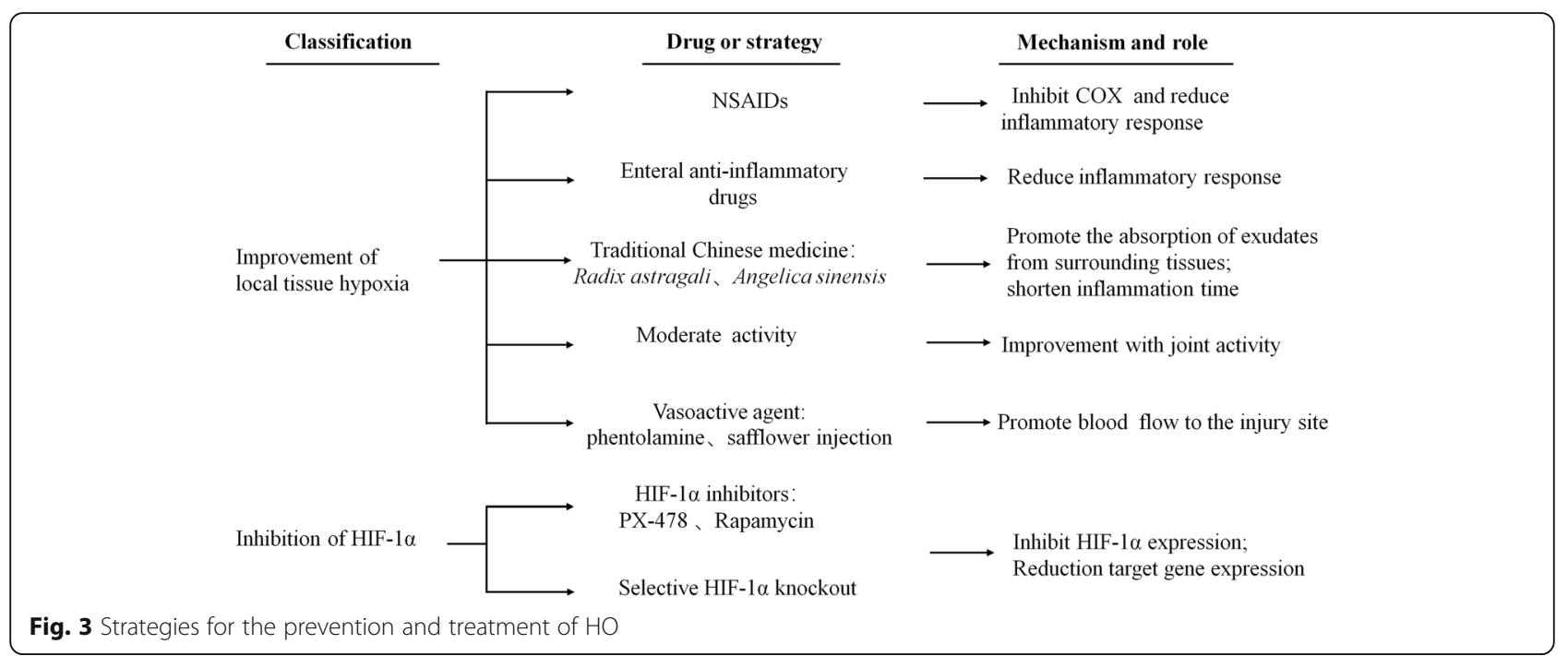

supply. The main reason for this link is that inflammation often releases inflammatory mediators that cause vascular blockage, blood circulation disorders, and the propagation of pathogens in infected cells after trauma induces hypoxia [13]. In addition, these inflammatory factors play important regulatory roles in the expression and activity of HIF-1 $\alpha$ and its downstream targets [9698]. Therefore, management of local hypoxia is mainly carried out through reducing inflammation and improving blood supply.

1) Nonsteroidal anti-inflammatory drugs (NSAIDs): NSAIDs have been used clinically for the prophylaxis of HO. The mechanism of action of NSAID is the delayed formation of $\mathrm{HO}$ by reducing the inflammatory response [99]. Commonly used NSAIDs include indomethacin and ibuprofen, but nonspecific NSAIDs are prone to developing peptic ulcers and other complications that have a greater adverse effect on the gastrointestinal tract. Hence so the use of selective COX-2 inhibitors is recommended for the prevention of $\mathrm{HO}$ [100].

2) Topical anti-inflammatory drugs: $\mathrm{HO}$ is induced after the patient experiences severe trauma. At present, the blood alkaline phosphatase concentration and erythrocyte sedimentation rates (ESR) are regularly tested in the clinic to determine the stage of ossification [101], especially when the ESR indexis high, which indicates that $\mathrm{HO}$ is in its active and late stages. The key to lowering the ESR index is to reduce inflammation of the wound with local ice application, as well as the external application of Qinghua Zhitong San and moderate debridement.

3) Oral and external use of traditional Chinese medicine: Oral and external use of traditional Chinese medicine improves microcirculation of the injured area and promotes the absorption of edema fluid, pooled blood and inflammatory exudate of the surrounding tissues [102]. Furthermore, the application of traditional Chinese medicine, such as Angelica and other antipyretic and analgesic Chinese herbal medicines relievethe degeneration of local muscle fibers and shorten the inflammatory reaction time [103].

4) Moderate activity: Clinical trials have shown that joint loosening during inactive ectopic ossification and complete maturation can effectively reduce ossification and help joint activity. Furthermore, in a rabbit model of trauma-induced $\mathrm{HO}$, forced fixation of the animal's body aggravated the occurrence of HO [104]. This finding indicates that after the soft tissue is traumatized and subjected to longterm compression, tissue hypoxia promotes $\mathrm{HO}$ due to poor blood circulation. Therefore, moderate activity is beneficial to prevent the occurrence of $\mathrm{HO}$ after injury.

5) Vasodilator drugs: Vasodilator drugs, such as phentolamine and the Chinese medicine safflower injection, increase the blood supply at the injured area and decrease the hypoxic microenvironment to prevent contracture and calcification of the joint capsule and surrounding muscles, preventing $\mathrm{HO}$ [105]. Clinical studies have shown that the use of safflower injection, like blood stasis drugs, has a certain inhibitory effect on traumatic HO [106].

\section{Inhibition of HIF-1a}

PX-478 is a selective molecular HIF- $1 \alpha$ inhibitor [107].PX-478 effectively inhibits the transcription and translation of HIF-1 $\alpha$ under normal or hypoxic conditions [107], with translation inhibition as the main mechanism. PX-478 also inhibits HIF-1 $\alpha$ deubiquitination. Rapamycin 
inhibits mainly the translation of the HIF- $1 \alpha$ by blocking the mTOR signaling pathway, but does not alter the transcription of HIF-1 $\alpha$. Rapamycin is also very effective in inhibiting hypoxia-induced expression of mTOR and VEGF [108].

The study has shown that the inhibition of HIF- $1 \alpha$ reduces $\mathrm{HO}$ precursor cells and decreases the expression of SOX-9, leading to a decrease in the volume of HO. No HO precursor cell aggregation or ectopic bone formation are observed after a conditional knockdown of HIF- $1 \alpha$ in mice $[12,109]$. Animal studies have found that the administration of $\mathrm{PX}-478$ to an $\mathrm{HO}$ mouse model after 3 weeks significantly reduces cartilage protoplasts, as confirmed by histological evaluation. Furthermore, the study has found a clear decrease in the volume of ectopic bone when the fifth and ninth weeks are compared. PX-478 treatment completely inhibits $\mathrm{HO}$ of the soft tissue [12]. In addition, PX-478 downregulates hypoxia-mediated VEGF expression(with no effect under normal conditions), but the effects of downregulated VEGF expression under hypoxic conditions

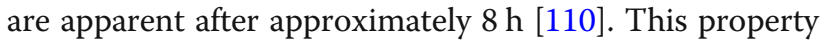
increases its potential for prevention and treatment of HO. Similarly, the use of rapamycin significantly reduces the production of trauma-induced and hereditary $\mathrm{HO}$ in mice, with some mice not showing any $\mathrm{HO}$ at all $[12,111]$. After targeted knock out of HIF-1 $\alpha$ in mice, the number of $\mathrm{HO}$ precursor cells is significantly reduced, and ectopic bone formation is reduced. Notably, rapamycin is now undergoing clinical trials for its use in $\mathrm{HO}$ [112].

\section{Conclusions}

This review highlights the role of the hypoxic microenvironment in promoting $\mathrm{HO}$, which primarily activates HIF and mediates members of its signaling pathways including BMP, VEGF, and NRP-1. First, hypoxia is a pathological process that emerges when tissue damage occurs; hypoxia and HIF- $1 \alpha$ are inextricably linked. HIF- $1 \alpha$ plays a central role in the regulation of multiple signal factors as follows. 1) The upregulation of BMP signaling factors promotes ectopic bone formation. 2) The upregulation of VEGF signaling promotes vascular endothelial growth and angiogenesis to regulate ectopic bone and cartilage formation. 3) The downregulation of NRP-1 inhibits osteoclast differentiation and increases abnormal osteogenesis in bone metabolism. Therefore, it is reasonable to conclude that HIF- $1 \alpha$ is a core hub in the signaling pathway that induces $\mathrm{HO}$. Blockade of the HIF- $1 \alpha$ activity would prevent the progression of HO. Since hypoxia is a direct cause of HIF$1 \alpha$ up-regulation, in addition to the use of HIF- $1 \alpha$ targeting inhibitors, management of the hypoxic microenvironment could down-regulate HIF- $1 \alpha$ and prevent HO. The hypoxic microenvironment is mainly related to inflammation and blood circulation disorders. Various drugs alleviate the inflammatory response and improve the ischemic state to change local hypoxia. These drugs can be used to prevent HO. Future methods to prevent and treat $\mathrm{HO}$ could be based on these findings:1) Tissue damage is a prerequisite of $\mathrm{HO}$ that promotes the progression of hereditary HO. Therefore, anti-inflammatory drugs and drugs that target diastolic blood vessels can be used to improve the hypoxic microenvironment at injured sites to prevent HO. 2) Exploration of the mechanism of HO should continue, and whether HIF- $1 \alpha$ engages in crosstalk with other signaling pathways involved in $\mathrm{HO}$ should be investigated, which will strengthen HIF-1 $\alpha$ as a targeted therapy for HO. 3) We should strive to stop $\mathrm{HO}$ in its early stages by improving hypoxia and inhibiting HIF-1 $\alpha$. Although the current understanding of hypoxia and $\mathrm{HO}$ remains very limited, we have nonetheless found that hypoxia and HIF-1 $\alpha$ play a key role in the initiation of HO. This review describes explicitly how hypoxia induces $\mathrm{HO}$ and effective strategies against hypoxia and HIF- $1 \alpha$. Further understanding of the mechanism of $\mathrm{HO}$ will provide new strategies for $\mathrm{HO}$ treatment.

\section{Abbreviations}

Act A: Activin A; AHO: Acquired HO Heterotopic ossification; BMPs: Bone morphogenetic proteins; COX-2: Cyclooxygenase-2; CTPCs: Connective tissue progenitor cells; FOP: Fibrodysplasia ossificans progressiva; HIF: Hypoxiainducible factor; HIF-1a: Hypoxia-inducible factor-1a; HIF-1 $\beta$ : Hypoxiainducible factor-1 $\beta$; HIF-2a: Hypoxia-inducible factor-2a; HIF-3a: Hypoxiainducible factor-3a; HO: Heterotopic ossification; ITAM: Immunoreceptor tyosine-based activation motif; mACVR1: Mutant Activin receptor A type1; mTOR: Mammalian target of rapamycin; NF-kB: Nuclear factor kappa beta; NRP-1: Neuropilin-1; NSAID: Nonsteroidal Antiinflammatory Drugs; $\mathrm{POH}$ : Progressive osseous heteroplasia.; Runx-2: Runt-related transcription factor 2; Sema3A: Semaphorin 3A; VEGF: Vascular endothelial growth factor

\section{Acknowledgements}

Not applicable.

\section{Authors' contributions}

Review conception and design: HL, YF Hand XY W. Drafting of the article: YF $\mathrm{H}$ and $\mathrm{HL}$. All authors read and approved the final manuscript.

\section{Funding}

This work was supported by grants from National Natural Science

Foundation of China [grant numbers: 31900852]; Natural Science Foundation of Jiangxi Province [grant numbers: 2018BAB215012]; Key project of Natural Science Foundation of Jiangxi Province [grant numbers: 20192ACB21026] and Nanchang University and Young Teachers Research and Development Fund Project from Jiangxi medical college of Nanchang University [grant numbers: PY201801].

\section{Availability of data and materials Not applicable.}

Ethics approval and consent to participate Not applicable.

Consent for publication

Not applicable.

Competing interests

The authors declare that they have no competing interests. 


\section{Author details}

'First Clinical Medical School, Nanchang University, Nanchang 330006, Jiangxi Province, China. ${ }^{2}$ Department of Pathophysiology, School of Basic Medical Sciences, Nanchang University, 461 BaYi Avenue, Nanchang 330006, Jiangxi Province, China.

Received: 25 October 2019 Accepted: 2 January 2020

Published online: 07 February 2020

\section{References}

1. Edwards DS, Clasper JC. Heterotopic ossification: a systematic review. J R Army Med Corps. 2015;161:315-21.

2. Ranganathan K, Loder S, Agarwal S, Wong WW, Forsberg J, Davis TA, Wang S, James AW, Levi B. Heterotopic ossification: basic-science principles and clinical correlates. J Bone Joint Surg Am. 2015:97:1101-11.

3. Xu R, Hu J, Zhou X, Yang Y. Heterotopic ossification: mechanistic insights and clinical challenges. Bone. 2018;109:134-42.

4. Chalmers J, Gray DH, Rush J. Observations on the induction of bone in soft tissues. J Bone Joint Surg Br. 1975;57:36-45.

5. Shore EM, Kaplan FS. Inherited human diseases of heterotopic bone formation. Nat Rev Rheumatol. 2010;6:518-27.

6. Olmsted-Davis E, Gannon FH, Ozen M, Ittmann MM, Gugala Z, Hipp JA, Moran KM, Fouletier-Dilling CM, Schumara-Martin S, Lindsey RW, et al. Hypoxic adipocytes pattern early heterotopic bone formation. Am J Pathol. 2007;170:620-32

7. Winkler S, Niedermair T, Fuchtmeier B, Grifka J, Grassel S, Anders S, Heers G, Wagner $F$. The impact of hypoxia on mesenchymal progenitor cells of human skeletal tissue in the pathogenesis of heterotopic ossification. Int Orthop. 2015;39:2495-501.

8. Bogdanovski DA, DiFazio LT, Bogdanovski AK, Csoka B, Jordan GB, Paul ER, Antonioli L, Pilip SA, Nemeth ZH. Hypoxia-inducible-factor-1 in trauma and critical care. J Crit Care. 2017:42:207-12.

9. Sailhamer EA, Li Y, Smith EJ, Liu B, Shuja F, Soupir CP, DeMoya MA, Velmahos GC, Alam HB. Hypoxic "second hit" in leukocytes from trauma patients: modulation of the immune response by histone deacetylase inhibition. Cytokine. 2010;49:303-11.

10. Lu G, Tandang-Silvas MR, Dawson AC, Dawson TJ, Groppe JC. Hypoxiaselective allosteric destabilization of activin receptor-like kinases: a potential therapeutic avenue for prophylaxis of heterotopic ossification. Bone. 2018; 112:71-89.

11. Baran N, Konopleva M. Molecular pathways: hypoxia-activated prodrugs in cancer therapy. Clin Cancer Res. 2017;23:2382-90.

12. Agarwal S, Loder S, Brownley C, Cholok D, Mangiavini L, Li J, Breuler C, Sung HH, Li S, Ranganathan K, et al. Inhibition of Hif1alpha prevents both traumainduced and genetic heterotopic ossification. Proc Natl Acad Sci U S A. 2016:113:E338-47

13. Wang H, Lindborg C, Lounev V, Kim JH, McCarrick-Walmsley R, Xu M, Mangiavini L, Groppe JC, Shore EM, Schipani E, et al. Cellular hypoxia promotes heterotopic ossification by amplifying BMP signaling. J Bone Miner Res. 2016:31:1652-65.

14. Semenza GL. Hypoxia-inducible factors in physiology and medicine. Cell. 2012;148:399-408.

15. Lin L, Shen $Q$, Leng $H$, Duan $X, F u X, Y u$ C. Synergistic inhibition of endochondral bone formation by silencing Hif1alpha and Runx2 in traumainduced heterotopic ossification. Mol Ther. 2011:19:1426-32.

16. Kawao N, Yano M, Tamura Y, Okumoto K, Okada K, Kaji H. Role of osteoclasts in heterotopic ossification enhanced by fibrodysplasia ossificans progressiva-related activin-like kinase 2 mutation in mice. J Bone Miner Metab. 2016:34:517-25.

17. Dey D, Wheatley BM, Cholok D, Agarwal S, Yu PB, Levi B, Davis TA. The traumatic bone: trauma-induced heterotopic ossification. Transl Res. 2017; 186:95-111.

18. van Kuijk AA, Geurts AC, van Kuppevelt HJ. Neurogenic heterotopic ossification in spinal cord injury. Spinal Cord. 2002;40:313-26.

19. Venier LH, Ditunno JF Jr. Heterotopic ossification in the paraplegic patient Arch Phys Med Rehabil. 1971:52:475-9.

20. Davis EL, Davis AR, Gugala Z, Olmsted-Davis EA. Is heterotopic ossification getting nervous?: the role of the peripheral nervous system in heterotopic ossification. Bone. 2018;109:22-7.

21. Hino K, Ikeya M, Horigome K, Matsumoto Y, Ebise H, Nishio M, Sekiguchi K, Shibata M, Nagata S, Matsuda S, Toguchida J. Neofunction of ACVR1 in fibrodysplasia ossificans progressiva. Proc Natl Acad Sci U S A. 2015;112: 15438-43.

22. Lin L, Shen Q, Xue T, Yu C. Heterotopic ossification induced by Achilles tenotomy via endochondral bone formation: expression of bone and cartilage related genes. Bone. 2010;46:425-31.

23. Peterson JR, De La Rosa S, Sun H, Eboda O, Cilwa KE, Donneys A, Morris M, Buchman SR, Cederna PS, Krebsbach PH, et al. Burn injury enhances bone formation in heterotopic ossification model. Ann Surg. 2014;259:993-8.

24. Zhang $\mathrm{H}$, Barralet JE. Mimicking oxygen delivery and waste removal functions of blood. Adv Drug Deliv Rev. 2017;122:84-104.

25. Semenza GL. Hypoxia-inducible factor 1 (HIF-1) pathway. Sci STKE. 2007; 2007:cm8.

26. Almendros I, Montserrat JM, Ramirez J, Torres M, Duran-Cantolla J, Navajas $D$, Farre R. Intermittent hypoxia enhances cancer progression in a mouse model of sleep apnoea. Eur Respir J. 2012:39:215-7.

27. Mohyeldin A, Garzon-Muvdi T, Quinones-Hinojosa A. Oxygen in stem cell biology: a critical component of the stem cell niche. Cell Stem Cell. 2010;7:150-61.

28. Jungermann K, Kietzmann T. Role of oxygen in the zonation of carbohydrate metabolism and gene expression in liver. Kidney Int. 1997;51: 402-12.

29. Eltzschig HK, Carmeliet P. Hypoxia and inflammation. N Engl J Med. 2011; 364:656-65

30. Li M, Kim WY. Two sides to every story: the HIF-dependent and HIFindependent functions of pVHL. J Cell Mol Med. 2011;15:187-95.

31. Sendoel A, Hengartner MO. Apoptotic cell death under hypoxia. Physiology (Bethesda). 2014;29:168-76.

32. Bensaid S, Fabre C, Fourneau J, Cieniewski-Bernard C. Impact of different methods of induction of cellular hypoxia: focus on protein homeostasis signaling pathways and morphology of C2C12 skeletal muscle cells differentiated into myotubes. J Physiol Biochem. 2019:75:367-77.

33. Olcina MM, Leszczynska KB, Senra JM, Isa NF, Harada H, Hammond EM. H3K9me3 facilitates hypoxia-induced p53-dependent apoptosis through repression of APAK. Oncogene. 2016;35:793-9.

34. Bracken CP, Fedele AO, Linke S, Balrak W, Lisy K, Whitelaw ML, Peet DJ. Cellspecific regulation of hypoxia-inducible factor (HIF)-1alpha and HIF-2alpha stabilization and transactivation in a graded oxygen environment. J Biol Chem. 2006;281:22575-85

35. Araldi E, Schipani E. Hypoxia, HIFs and bone development. Bone. 2010;47:190-6.

36. Pfander D, Cramer T, Schipani E, Johnson RS. HIF-1alpha controls extracellular matrix synthesis by epiphyseal chondrocytes. J Cell Sci. 2003; 116:1819-26.

37. Amarilio R, Viukov SV, Sharir A, Eshkar-Oren I, Johnson RS, Zelzer E. HIF1alpha regulation of Sox9 is necessary to maintain differentiation of hypoxic prechondrogenic cells during early skeletogenesis. Development. 2007:134:3917-28.

38. Steinbrech DS, Mehrara BJ, Saadeh PB, Chin G, Dudziak ME, Gerrets RP, Gittes GK, Longaker MT. Hypoxia regulates VEGF expression and cellular proliferation by osteoblasts in vitro. Plast Reconstr Surg. 1999;104:738-47.

39. Lin SC, Liao WL, Lee JC, Tsai SJ. Hypoxia-regulated gene network in drug resistance and cancer progression. Exp Biol Med (Maywood). 2014;239:779-92.

40. Semenza GL. Oxygen sensing, hypoxia-inducible factors, and disease pathophysiology. Annu Rev Pathol. 2014;9:47-71.

41. Van Meir E. Hypoxia-mediated selection of cells with diminished apoptotic potential to solid tumours. Neurosurgery. 1996;39:878-9.

42. Cummins EP, Keogh CE, Crean D, Taylor CT. The role of HIF in immunity and inflammation. Mol Asp Med. 2016;47-48:24-34.

43. Rankin EB, Giaccia AJ, Schipani E. A central role for hypoxic signaling in cartilage, bone, and hematopoiesis. Curr Osteoporos Rep. 2011;9:46-52.

44. Prabhakar NR, Semenza GL. Adaptive and maladaptive cardiorespiratory responses to continuous and intermittent hypoxia mediated by hypoxiainducible factors 1 and 2. Physiol Rev. 2012;92:967-1003.

45. Robins JC, Akeno N, Mukherjee A, Dalal RR, Aronow BJ, Koopman P, Clemens TL. Hypoxia induces chondrocyte-specific gene expression in mesenchymal cells in association with transcriptional activation of Sox9. Bone. 2005;37:313-22.

46. Drouin G, Couture V, Lauzon MA, Balg F, Faucheux N, Grenier G. Muscle injury-induced hypoxia alters the proliferation and differentiation potentials of muscle resident stromal cells. Skelet Muscle. 2019:9:18.

47. Convente MR, Wang H, Pignolo RJ, Kaplan FS, Shore EM. The immunological contribution to heterotopic ossification disorders. Curr Osteoporos Rep. 2015;13:116-24. 
48. Agrawal R, Pandey P, Jha P, Dwivedi V, Sarkar C, Kulshreshtha R. Hypoxic signature of microRNAs in glioblastoma: insights from small RNA deep sequencing. BMC Genomics. 2014;15:686.

49. Devraj G, Beerlage C, Brune B, Kempf VA. Hypoxia and HIF-1 activation in bacterial infections. Microbes Infect. 2017;19:144-56.

50. Cash TP, Pan Y, Simon MC. Reactive oxygen species and cellular oxygen sensing. Free Radic Biol Med. 2007;43:1219-25.

51. Dey D, Bagarova J, Hatsell SJ, Armstrong KA, Huang L, Ermann J, Vonner AJ, Shen Y, Mohedas AH, Lee A, et al. Two tissue-resident progenitor lineages drive distinct phenotypes of heterotopic ossification. Sci Transl Med. 2016;8: 366ra163.

52. Wang H, Shore EM, Pignolo RJ, Kaplan FS. Activin a amplifies dysregulated BMP signaling and induces chondro-osseous differentiation of primary connective tissue progenitor cells in patients with fibrodysplasia ossificans progressiva (FOP). Bone. 2018;109:218-24.

53. Semenza GL. Hydroxylation of HIF-1: oxygen sensing at the molecular level. Physiology (Bethesda). 2004;19:176-82.

54. Vogelberg $\mathrm{KH}$, Konig M. Hypoxia of diabetic feet with abnormal arterial blood flow. Clin Investig. 1993;71:466-70.

55. Wu C, Li X, Zhang D, Xu B, Hu W, Zheng X, Zhu D, Zhou Q, Jiang J, Wu C. IL-1 beta-mediated up-regulation of WT1D via miR-144-3p and their synergistic effect with NF-kappaB/COX-2/HIF-1alpha pathway on cell proliferation in LUAD. Cell Physiol Biochem. 2018;48:2493-502.

56. Semenza GL. Oxygen homeostasis. Wiley Interdiscip Rev Syst Biol Med. 2010:2:336-61

57. Lee HC, Tsai SJ. Endocrine targets of hypoxia-inducible factors. J Endocrinol. 2017;234:R53-65.

58. Zhao Q, Ishibashi M, Hiasa K, Tan C, Takeshita A, Egashira K. Essential role of vascular endothelial growth factor in angiotensin II-induced vascular inflammation and remodeling. Hypertension. 2004;44:264-70.

59. Tseng WP, Yang SN, Lai CH, Tang CH. Hypoxia induces BMP-2 expression via ILK, Akt, mTOR, and HIF-1 pathways in osteoblasts. J Cell Physiol. 2010;223:810-8.

60. Liu YQ, Han XF, Bo JX, Ma HP. Wedelolactone enhances Osteoblastogenesis but inhibits Osteoclastogenesis through Sema3A/NRP1/PlexinA1 pathway. Front Pharmacol. 2016;7:375.

61. Wan X, Shen N, Mendoza A, Khanna C, Helman U. CCl-779 inhibits rhabdomyosarcoma xenograft growth by an antiangiogenic mechanism linked to the targeting of mTOR/Hif-1alpha/NEGF signaling. Neoplasia. 2006;8:394-401.

62. Sedlmeier G, Sleeman JP. Extracellular regulation of BMP signaling: welcome to the matrix. Biochem Soc Trans. 2017:45:173-81.

63. Sieber C, Kopf J, Hiepen C, Knaus P. Recent advances in BMP receptor signaling. Cytokine Growth Factor Rev. 2009;20:343-55.

64. Lafont JE, Poujade FA, Pasdeloup M, Neyret P, Mallein-Gerin F. Hypoxia potentiates the BMP-2 driven COL2A1 stimulation in human articular chondrocytes via p38 MAPK. Osteoarthr Cartil. 2016;24:856-67.

65. Katagiri T, Watabe T. Bone Morphogenetic Proteins. Cold Spring Harb Perspect Biol. 2016;8(6):a021899. https://doi.org/10.1101/cshperspect.a021899.

66. Rittenberg B, Partridge E, Baker G, Clokie C, Zohar R, Dennis JW, Tenenbaum HC. Regulation of BMP-induced ectopic bone formation by Ahsg. J Orthop Res. 2005;23:653-62.

67. Leblanc E, Trensz F, Haroun S, Drouin G, Bergeron E, Penton CM, Montanaro F, Roux S, Faucheux N, Grenier G. BMP-9-induced muscle heterotopic ossification requires changes to the skeletal muscle microenvironment. Bone Miner Res. 2011;26:1166-77.

68. Grenier G, Leblanc E, Faucheux N, Lauzier D, Kloen P, Hamdy RC. BMP-9 expression in human traumatic heterotopic ossification: a case report. Skelet Muscle. 2013:3:29.

69. Shafritz AB, Shore EM, Gannon FH, Zasloff MA, Taub R, Muenke M, Kaplan FS. Overexpression of an osteogenic morphogen in fibrodysplasia ossificans progressiva. N Engl J Med. 1996;335:555-61.

70. Fontebasso AM, Papillon-Cavanagh S, Schwartzentruber J, Nikbakht $\mathrm{H}$, Gerges N, Fiset PO, Bechet D, Faury D, De Jay N, Ramkissoon LA, et al. Recurrent somatic mutations in ACVR1 in pediatric midline high-grade astrocytoma. Nat Genet. 2014:46:462-6.

71. Buczkowicz P, Hoeman C, Rakopoulos P, Pajovic S, Letourneau L, Dzamba $M$, Morrison A, Lewis $P$, Bouffet $E$, Bartels $U$, et al. Genomic analysis of diffuse intrinsic pontine gliomas identifies three molecular subgroups and recurrent activating ACVR1 mutations. Nat Genet. 2014;46:451-6.

72. Dizon ML, Maa T, Kessler JA. The bone morphogenetic protein antagonist noggin protects white matter after perinatal hypoxia-ischemia. Neurobiol Dis. 2011;42:318-26.
73. Ferrara N, Henzel WJ. Pituitary follicular cells secrete a novel heparin-binding growth factor specific for vascular endothelial cells. Biochem Biophys Res Commun. 1989;161:851-8.

74. Patel-Hett S, D'Amore PA. Signal transduction in vasculogenesis and developmental angiogenesis. Int J Dev Biol. 2011;55:353-63.

75. Couffinhal T, Kearney M, Witzenbichler B, Chen D, Murohara T, Losordo DW Symes J, Isner JM. Vascular endothelial growth factor/vascular permeability factor (VEGFNPF) in normal and atherosclerotic human arteries. Am J Pathol. 1997:150:1673-85.

76. Zhang $\mathrm{X}$, Lassila M, Cooper ME, Cao Z. Retinal expression of vascular endothelial growth factor is mediated by angiotensin type 1 and type 2 receptors. Hypertension. 2004;43:276-81.

77. Smith GA, Fearnley GW, Harrison MA, Tomlinson DC, Wheatcroft SB, Ponnambalam S. Vascular endothelial growth factors: multitasking functionality in metabolism, health and disease. J Inherit Metab Dis. 2015;38: 753-63.

78. Kaigler D, Wang Z, Horger K, Mooney DJ, Krebsbach PH. VEGF scaffolds enhance angiogenesis and bone regeneration in irradiated osseous defects. J Bone Miner Res. 2006;21:735-44.

79. Zhao C, Popel AS. Computational model of MicroRNA control of HIF-VEGF pathway: insights into the pathophysiology of ischemic vascular disease and Cancer. PLoS Comput Biol. 2015;11:e1004612.

80. Chen Z, Lai TC, Jan YH, Lin FM, Wang WC, Xiao H, Wang YT, Sun W, Cui X, Li YS, et al. Hypoxia-responsive miRNAs target argonaute 1 to promote angiogenesis. J Clin Invest. 2013;123:1057-67.

81. Tian XB, Sun L, Yang SH, Fu RY, Wang L, Lu TS, Zhang YK, Fu DH. Ectopic osteogenesis of mouse bone marrow stromal cells transfected with BMP 2/ VEGF(165) genes in vivo. Orthop Surg. 2009;1:322-5.

82. Kakudo N, Kusumoto K, Wang YB, Iguchi Y, Ogawa Y. Immunolocalization of vascular endothelial growth factor on intramuscular ectopic osteoinduction by bone morphogenetic protein-2. Life Sci. 2006;79:1847-55.

83. Ortega N, Wang K, Ferrara N, Werb Z, Vu TH. Complementary interplay between matrix metalloproteinase-9, vascular endothelial growth factor and osteoclast function drives endochondral bone formation. Dis Model Mech. 2010;3:224-35

84. Jacobsen KA, Al-Aql ZS, Wan C, Fitch JL, Stapleton SN, Mason ZD, Cole RM, Gilbert SR, Clemens TL, Morgan EF, et al. Bone formation during distraction osteogenesis is dependent on both VEGFR1 and VEGFR2 signaling. J Bone Miner Res. 2008;23:596-609.

85. Street J, Bao M, deGuzman L, Bunting S, Peale FV Jr, Ferrara N, Steinmetz H, Hoeffel J, Cleland JL, Daugherty A, et al. Vascular endothelial growth factor stimulates bone repair by promoting angiogenesis and bone turnover. Proc Natl Acad Sci U S A. 2002;99:9656-61.

86. Saad S, Dharmapatni A, Crotti TN, Cantley MD, Algate K, Findlay DM, Atkins GJ, Haynes DR. Semaphorin-3a, neuropilin-1 and plexin-A1 in prostheticparticle induced bone loss. Acta Biomater. 2016;30:311-8.

87. Hayashi M, Nakashima T, Taniguchi M, Kodama T, Kumanogoh A, Takayanagi H. Osteoprotection by semaphorin 3A. Nature. 2012;485:69-74

88. Pellet-Many C, Frankel P, Evans IM, Herzog B, Junemann-Ramirez M, Zachary IC. Neuropilin-1 mediates PDGF stimulation of vascular smooth muscle cell migration and signalling via p130Cas. Biochem J. 2011;435:609-18.

89. Misra RM, Bajaj MS, Kale VP. Vasculogenic mimicry of HT1080 tumour cells in vivo: critical role of HIF-1alpha-neuropilin-1 axis. PLoS One. 2012;7:e50153.

90. Yagi M, Miyamoto T, Toyama Y, Suda T. Role of DC-STAMP in cellular fusion of osteoclasts and macrophage giant cells. J Bone Miner Metab. 2006;24: $355-8$.

91. Upadhyay J, Farr OM, Mantzoros CS. The role of leptin in regulating bone metabolism. Metabolism. 2015;64:105-13.

92. Kolar P, Gaber T, Perka C, Duda GN, Buttgereit F. Human early fracture hematoma is characterized by inflammation and hypoxia. Clin Orthop Relat Res. 2011;469:3118-26.

93. Murata K, Fang C, Terao C, Giannopoulou EG, Lee YJ, Lee MJ, Mun SH, Bae S, Qiao Y, Yuan R, et al. Hypoxia-sensitive COMMD1 integrates signaling and cellular metabolism in human macrophages and suppresses osteoclastogenesis. Immunity. 2017:47:66-79 e65.

94. Jensen LL, Halar E, Little JW, Brooke MM. Neurogenic heterotopic ossification. Am J Phys Med. 1987;66:351-63.

95. Vanden Bossche LC, Van Maele G, Wojtowicz I, Bru I, Decorte T, De Muynck M, Rimbaut S, Vanderstraeten G. Free radical scavengers versus methylprednisolone in the prevention of experimentally induced heterotopic ossification. J Orthop Res. 2009;27:748-51. 
96. Haddad JJ, Harb HL. Cytokines and the regulation of hypoxia-inducible factor (HIF)-1alpha. Int Immunopharmacol. 2005;5:461-83.

97. Zinkernagel AS, Johnson RS, Nizet V. Hypoxia inducible factor (HIF) function in innate immunity and infection. J Mol Med (Berl). 2007;85:1339-46.

98. Walmsley SR, Print C, Farahi N, Peyssonnaux C, Johnson RS, Cramer T, Sobolewski A, Condliffe AM, Cowburn AS, Johnson N, Chilvers ER. Hypoxiainduced neutrophil survival is mediated by HIF-1alpha-dependent NFkappaB activity. J Exp Med. 2005;201:105-15.

99. Ma R, Chen GH, Zhao $L$, Zhai XC. Efficacy of naproxen prophylaxis for the prevention of heterotopic ossification after hip surgery: a meta-analysis. J Orthop Surg Res. 2018;13:48.

100. Xue D, Zheng Q, Li H, Qian S, Zhang B, Pan Z. Selective COX-2 inhibitor versus nonselective COX-1 and COX-2 inhibitor in the prevention of heterotopic ossification after total hip arthroplasty: a meta-analysis of randomised trials. Int Orthop. 2011:35:3-8.

101. Ploumis A, Donovan JM, Olurinde MO, Clark DM, Wu JC, Sohn DJ, O'Connor KC. Association between alendronate, serum alkaline phosphatase level, and heterotopic ossification in individuals with spinal cord injury. J Spinal Cord Med. 2015;38:193-8.

102. Tasneem S, Liu B, Li B, Choudhary MI, Wang W. Molecular pharmacology of inflammation: medicinal plants as anti-inflammatory agents. Pharmacol Res. 2019:139:126-40.

103. Ma J, Huang J, Hua S, Zhang Y, Zhang Y, Li T, Dong L, Gao Q, Fu X. The ethnopharmacology, phytochemistry and pharmacology of Angelica biserrata - a review. J Ethnopharmacol. 2019;231:152-69.

104. Desai MJ, Ramalingam H, Ruch DS. Heterotopic ossification after the arthroscopic treatment of lateral epicondylitis. Hand (N Y). 2017;12:NP32-6.

105. Wang KH, Li SF, Zhao Y, Li HX, Zhang LW. In Vitro Anticoagulant Activity and Active Components of Safflower Injection. Molecules. 2018;23(1):170 https://doi.org/10.3390/molecules23010170.

106. Joyner MJ, Casey DP. Muscle blood flow, hypoxia, and hypoperfusion. J Appl Physiol (1985). 2014;116:852-7.

107. Lee K, Kim HM. A novel approach to cancer therapy using PX-478 as a HIF1alpha inhibitor. Arch Pharm Res. 2011;34:1583-5.

108. Liu NN, Zhao N, Cai N. Suppression of the proliferation of hypoxia-induced retinal pigment epithelial cell by rapamycin through the /mTOR/HIF-1alpha/ VEGF/ signaling. IUBMB Life. 2015;67:446-52.

109. Wu J, Ren B, Shi F, Hua P, Lin H. BMP and mTOR signaling in heterotopic ossification: does their crosstalk provide therapeutic opportunities? J Cell Biochem. 2019;120:12108-22.

110. Koh MY, Spivak-Kroizman T, Venturini S, Welsh S, Williams RR, Kirkpatrick DL, Powis G. Molecular mechanisms for the activity of PX-478, an antitumor inhibitor of the hypoxia-inducible factor-1alpha. Mol Cancer Ther. 2008;7:90-100.

111. Qureshi AT, Dey D, Sanders EM, Seavey JG, Tomasino AM, Moss K, Wheatley B, Cholok D, Loder S, Li J, et al. Inhibition of mammalian target of Rapamycin signaling with Rapamycin prevents trauma-induced heterotopic ossification. Am J Pathol. 2017;187:2536-45.

112. Kaplan FS, Zeitlin L, Dunn SP, Benor S, Hagin D, Al Mukaddam M, Pignolo RJ. Acute and chronic rapamycin use in patients with Fibrodysplasia Ossificans Progressiva: a report of two cases. Bone. 2018;109:281-4.

\section{Publisher's Note}

Springer Nature remains neutral with regard to jurisdictional claims in published maps and institutional affiliations.

Ready to submit your research? Choose BMC and benefit from:
- fast, convenient online submission
- thorough peer review by experienced researchers in your field
- rapid publication on acceptance
- support for research data, including large and complex data types
- gold Open Access which fosters wider collaboration and increased citations
- maximum visibility for your research: over 100M website views per year
At BMC, research is always in progress.
Learn more biomedcentral.com/submissions

